\title{
RANCANGAN MODEL PURWARUPA KEMASAN KOPI SPECIALTY
}

\section{DESIGN OF PROTOTYPE MODEL OFSPECIALTY COFFEE PACKAGING}

\author{
Zulkarnain $^{1}{ }^{*}$, Machfud $^{2)}$, Marimin $^{2)}$, Emmy Darmawati ${ }^{3)}$, Sugiarto $^{2)}$ \\ ${ }^{1)}$ Program Studi Teknologi Industri Cetak Kemasan, Jurusan Teknik Grafika dan Penerbitan, Politeknik Negeri Jakarta \\ Jl. Prof. DR. G.A. Siwabessy, Kampus Baru UI Depok, Jawa Barat 16424 \\ Email: zulkarnain@grafika.pnj.ac.id \\ ${ }^{2)}$ Program Studi Teknologi Industri Pertanian, Sekolah Pascasarjana, Institut Pertanian Bogor \\ 3)Program Studi Teknik Mesin dan Biosistem, Sekolah Pascasarjana, Institut Pertanian Bogor
}

Makalah: Diterima 3 Juli 2019; Diperbaiki 13 Januari 2020; Disetujui 10 Februari 2020

\begin{abstract}
Packaging design is a challenge for the development of micro-industries, especially to encounter high competition against well-known products. Unfortunately, most of micro-industries have limitations in term of packaging design and attractiveness. The purpose of this study was to design the right packaging prototype model for the micro-industries. The study applied the value engineering approach which consisted of information, creative, analysis, development, and recommendation stages. In the creative stage, the process included making the moodboards, sketches and digitizing designs as well as generating prototypes. Fuzzy AHP (Analytical Hierarchy Process) was applied in the analysis stage to obtain the weight of each performance parameter. From the analysis, it found that colour was the most significant parameter in determining packaging design of specialty coffee packaging. The most appropriate model recommendation as a representation of packaging for specialty coffee businesses for micro-scale industries was the flat bottom pouch type contained in alternative III.
\end{abstract}

Keywords: fuzzy AHP, packaging design, prototype, value engineering

ABSTRAK

Desain kemasan menjadi tantangan untuk perkembangan industri mikro terutama dalam menghadapi persaingan yang ketat terhadap produk-produk terkenal. Sayangnya industri mikro memiliki keterbatasan dalam menancang kemasan yang tepat dan kemasan yang memiliki daya tarik. Tujuan penelitian ini adalah mendesain model purwarupa kemasan yang tepat untuk industri mikro. Penelitian ini menerapkan pendekatan value engineering yang terdiri dari tahap informasi, kreatif, analisis, pengembangan, dan rekomendasi. Tahap kreatif dilakukan melalui proses pembuatan moodboard, sketsa, digitalisasi desain, hingga membuat alternatif purwarupa. Fuzzy AHP diterapkan pada tahap analisis untuk memperoleh bobot dari setiap parameter kinerja. Berdasarkan analisis parameter kinerja kemasan ditemukan bahwa warna merupakan parameter yang paling signifikan dalam merancang kemasan kopi specialty. Rekomendasi model yang paling tepat sebagai representasi kemasan untuk pelaku usaha kopi specialty untuk skala industri mikro adalah kemasan tipe flat bottom pouch yang terdapat pada alternatif III.

Kata kunci: desain kemasan, fuzzy AHP, purwarupa, value engineering

\section{PENDAHULUAN}

Kemasan dapat digunakan untuk menciptakan nilai yang kompetitif di pasar (Rundh, 2016). Sementara itu, Wahyudi dan Satriyono (2017) menyatakan bahwa kecenderungan belanja swalayan dan belanja online yang berkembang pesat saat ini telah memberi kemasan tugas baru untuk menarik perhatian konsumen. Sebagai kunci untuk menjual produk, kemasan harus baik secara visual agar konsumen mudah mengetahui, mengenal, dan tertarik pada produk yang dikemasnya.

Desain kemasan menjadi tantangan untuk perkembangan usaha mikro terutama dalam menghadapi persaingan yang ketat terhadap perusahaan besar atau produk luar negeri. Padahal, kualitas produk usaha mikro tidak kalah dengan produk luar, bahkan justru memiliki kekhasan tersendiri yang tidak diperoleh dari produk luar.
Salah-satunya produk kopi specialty dengan beragam single origin yang banyak diusahakan oleh industri mikro di Indonesia. Industri mikro berusaha memberikan kualitas kopi terbaik, namun sayangnya dalam hal desain kemasan masih kurang menarik. Hal ini karena kekurangan keterampilan dan pengetahuan terhadap desain kemasan (Auttarapong, 2012).

Industri mikro merupakan salah-satu kekuatan dalam pembangunan ekonomi di Indonesia. Agroindustri kopi terus tumbuh dan berkembang khususnya produk kopi specialty yang banyak diusahakan oleh industri mikro. Jenis produk ini memiliki kualitas dan harga yang relatif tinggi dibanding produk kopi komersil yang diproduksi oleh perusahaan besar. Usaha mikro berusaha menampakkan eksistensinya dalam bersaing dengan pabrikasi besar, sehingga usaha mikro harus kreatif, khususnya kreativitas kemasan produknya (Hidayat et al., 2014). Sayangnya industri mikro memiliki

*Penulis Korespodensi 
keterbatasan dalam memperoleh kemasan yang tepat dan memiliki daya tarik.

Peran kemasan sangat penting dalam menyampaikan pesan yang terkandung di dalam kemasan sehingga diharapkan dapat memikat (eyecatching) calon konsumen. Hess (2014) menyebutkan bahwa kualitas pengemasan memiliki peran penting dalam membangun hubungan yang menguntungkan antara merek dengan konsumen. Bagaimanapun produk yang baik harus dikemas dengan kemasan yang baik agar dapat mempengaruhi persepsi konsumen terhadap nilai dan kualitas suatu produk.

Kemasan merupakan tantangan bagi perkembangan dan kemajuan industri mikro. Banyak persoalan yang dihadapi ketika ingin memiliki kemasan yang tepat. Persoalan-persoalan tersebut adalah struktur kemasan, desain grafis, sampai pada pembuatan kemasan. Struktur kemasan biasanya terkait dengan bahan, ukuran, dan bentuk kemasan. Desain grafis biasanya terkait dengan apa yang ingin dikomunikasikan kepada konsumen.

Baik sisi desain struktur maupun desain grafis kemasan harus tepat agar kualitas kopi yang baik selalu terjaga dan persepsi kualitas kopi yang baik juga selalu melekat. Struktur kemasan berpengaruh dalam menjaga kualitas aroma dan rasa kopi dari paparan sinar matahari dan oksigen. Sementara desain grafis kemasan sangat penting dalam mempengaruhi perilaku konsumen terkait keputusan membeli. Dalam perancangan kemasan harus memberi perhatian pada pesan sebuah kemasan untuk disampaikan pada konsumen, baik pesan yang nyata (seperti kategori produk, brand, tipe konsumen, dan keuntungan yang ditawarkan produk) maupun pesan terselubung (seperti warna, bentuk, ukuran, dan tekstur) yang dapat menimbulkan kesan mewah (Natadjaja, 2007). Desain kemasan dapat menjadi solusi dalam menjawab tantangan pelaku usaha mikro.

Terdapat banyak desain kemasan kopi specialty ternama yang beredar di pasaran, namun masih banyak juga usaha mikro memiliki kemasan yang kurang menarik. Untuk itu diperlukan model kemasan yang dapat diikuti oleh pelaku usaha mikro. Penelitian ini bertujuan mendesain model purwarupa kemasan yang tepat untuk usaha mikro. Adapun manfaat penelitian ini adalah sebagai salah-satu inspirasi bagiberbagai pihak baikpelaku usaha, calon pelaku usaha, maupun desainer pemula dalam sebuah proses desain. Berdasarkan studi lapang dan literatur diperoleh bahwa jenis kemasan pouchuntuk kemasan kopi merupakan jenis kemasan yang trend dan palingrevolusionerkopi saat ini (DJIKM, 2007; Murniyati, 2009). Mudah dalam penggunaan menjadi salah satu alasan konsumen memilih jenis kemasan ini. Selain itu bagi pelaku usaha, pouch mudah diperoleh dalam jumlah yang sesuai dengan kebutuhan atau kemampuan usahanya.

Beberapa penelitian desain kemasan menggunakan pendekatan engineering design seperti Auttarapong (2012), Kun dan Xi (2017), dan Parada et al. (2019). Sementara itu ada juga penelitian desain kemasan yang menggunakan pendekatan graphic design seperti Halder et al. (2016), Hariono dan Zaini (2017). Berdasarkan kajian pustaka belum ditemukan penelitian yang mengintegrasikan kedua pendekatan tersebut. Penelitian ini mengintegrasikan keduanya, dimana pendekatan engineering design memiliki sifat yang lebih pasti, rasional, dan obyektif sedangkan graphic design memiliki sifat yang subyektif dan emosional.Pendekatan engineering design diterapkan dengan menggunakan metodevalue engineering (VE) yang kemudian dilengkapi dengan pendekatan graphic design pada tahap kreatif yang terdapat pada VE.Selain itu pada VE juga diterapkan metode fuzzy AHP tahap analisis. Penggunaan fuzzy dan AHP dimaksudkan agar memudahkan dalam proses penalaran secara bahasa (linguistic reasoning) namun konsistensi dalam penilaian tetap terjaga. Penerapan VE dimaksudkan untuk mengakomodasi kebutuhan baik teknis maupun kreatif untuk mencapai hasil yang optimal.

\section{METODE PENELITIAN}

\section{Kerangka Penelitian}

Penelitian ini diterapkan dalam bentuk studi kasus re-desain kemasan kopi untuk produk usaha mikro ARAKOPI yang berlokasi di Aceh Tengah, Indonesia. ARAKOPI yang didirikan pada tanggal 03 Agustus 2016 merupakan salah satu penggiat jenis kopi arabika Gayo (Aceh). Fokus utama penelitian ini adalah merancang kemasan kopi specialty dengan jenis pouch. Proses re-desain kemasan mengikuti tahapan value engineering, mulai dari tahap informasi sampai tahap rekomendasi. Pada tahap rekomendasi ditentukan model purwarupa yang paling tepat. Kerangka Pemikiran ditunjukkan pada Gambar 1.

\section{Metode Pengumpulan Data}

Pengumpulan data dilakukan melalui observasi lapang, literatur, diskusi dengan pelaku usaha, pakar, dan konsumen melalui wawancara mendalam dan kuesioner. Observasi lapang dilakukan dengan mengunjungi pameran kopi dan pemasok (supplier) kemasan kopi. Studi literatur dilakukan terhadap penelitian-penelitian sebelumnya terkait kopi dan kemasan. Diskusi dilakukan dengan pelaku usaha untuk menghasilkan ringkasan desain (design brief), sementara itu, diskusi dengan pakar untuk memperoleh penilaian matriks pembobotan kinerja kemasan. 


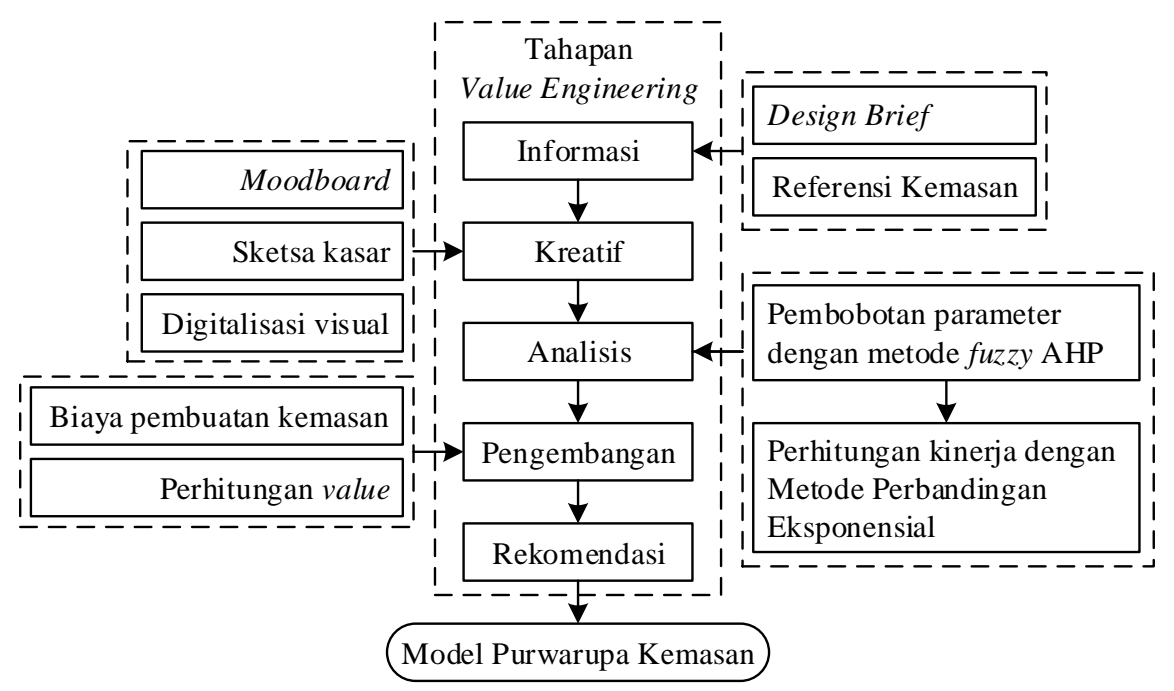

Gambar 1. Kerangka penelitian

Pakar dalam penelitian ini terdiri dari 1 peneliti desain kemasan, 2 akademisi desain grafis, 1 akademisi perancangan kemasan, dan 1 praktisi desain kemasan. Survei dilakukan secara purposive sampling terhadap 30 responden (konsumen umum) untuk memperoleh penilaian konsumen terhadap purwarupa alternatif. Responden terdiri dari 5 responden pada usia sekolah ( $\leq 25$ tahun), 23 responden pada usia kerja/muda (26 tahun - 45 tahun), dan 2 responden pada usia matang ( $\geq 46$ tahun).

\section{Metode Analisis Data}

Proses perancangan purwarupa dilakukan dengan metode value engineering. Menurut PEGR (2009), value engineering mengidentifikasi fungsi suatu produk atau layanan; menetapkan nilai untuk fungsi itu; dan menyediakan cara alternatif untuk mencapai fungsi yang diperlukan, dengan andal, dengan biaya keseluruhan terendah, melalui penggunaan teknik kreatif. Value engineering merupakan sarana yang sangat penting untuk mengarahkan pengetahuan dan aliran kreatif untuk menciptakan keunggulan kompetitif yang efisien (Cerqueiro et al., 2011). Sementara Jadhav dan Teli (2015) menyatakan bahwa teknik ini berkaitan dengan evaluasi dan akhirnya pemilihan kondisi yang lebih murah tetapi mencapai hasil yang optimal. Jadi, value engineering adalah metode untuk memecahkan masalah biaya dan teknis (PEGR, 2009). Tahapan value engineering terdiri dari tahap informasi, kreatif, analisis, pengembangan dan presentasi (Younker, 2003).

Tahap informasi merupakan tahap pengumpulan informasi mengenai objek yang dikaji. Informasi diperoleh melalui observasi lapang, studi literatur, dan wawancara. Observasi lapang dilakukan berupa kunjungan ke acara pameran kopi, seperti The Indonesia Coffee Expo 2018 di Blok M Square (Jakarta) dan Rembug Kopi Nusantara 2018 di SMESCO (Jakarta). Studi literatur dilakukan terhadap jurnal-jurnal ilmiah dan buku-buku yang terkait dengan kemasan dan kopi. Wawancara dilakukan terhadap pelaku usaha Arakopi dan konsumen kopi. Output pada tahap ini berupa ringkasan desain (design brief), copywriting required, dan spesifikasi alternatif struktur kemasan yang akan digunakan.

Tahap kreatif merupakan tahap pengembangan alternatif-alternatif yang memungkinkan. Tahap ini dilakukan melalui proses pembuatan moodboard, sketsa, dan digitalisasi desain. Moodboard merupakan referensi visual untuk pembuatan sketsa yang dapat diperoleh melalui googling kata kunci tertentu. Referensi tersebut berupa kumpulan warna-warna, foto, dan ilustrasi (gambar) yang terkait dengan ringkasan desain (Hadiprawiro, 2018). Sketsa merupakan gambaran konsep desain label secara visual dengan menggunakan pensil. Konsep yang masih berupa sketsa kemudian disempurnakan melalui proses digitalisasi desain menggunakan software adobe illustrator dan adobe photoshop. Desain label dicetak menggunakan bahan stiker kertas yang kemudian ditempel pada struktur (kemasan) pouch. Output pada tahap ini berupa alternatif-alternatif desain purwarupa kemasan.

Tahap analisis ini merupakan tahap analisis perhitungan pembobotan parameter kemasan dengan menggunakan metode Fuzzy AHP berdasarkan penilaian pakar. Penilaian pakar ini menggunakan perbandingan berpasangan dengan skala bilangan fuzzy triangular $\tilde{1}$ - $\tilde{9}$. Fungsi keanggotaan bilangan fuzzy triangular dapat dilihat pada Gambar 2 . 
(Sumber: Marimin et al., 2013)

\section{Gambar 2. Fungsi keanggotaan bilangan fuzzy triangular}

Fuzzy AHP merupakan teknik untuk perhitungan bobot relatif dari hierarki pembobotan matrik kinerja kemasan kopi specialty. Teknik ini digunakan dengan nilai $\alpha$ sebesar 0,5 yang menunjukkan bahwa para pakar memiliki tingkat kepercayaan rata-rata pada saat penilaian, dan indeks optimisme $(\omega)$ sebesar 0,5 yang menunjukkan bahwa penilaian yang diberikan tidak terlalu optimis dan tidak terlalu pesimis. Persamaan 1, 1, 3, 4, 5, dan 2 digunakan untuk menerjemahkan penilaian fuzzyAHP (Marimin et al., 2013).

$$
\tilde{1}_{a}=[1,3-2 \alpha]
$$

$\tilde{3}_{\alpha}=[1+2 \alpha, 5-2 \alpha] ; \tilde{3}_{\alpha}^{-1}=\left[\frac{1}{5-2 \alpha}, \frac{1}{1+2 \alpha}\right]$

$\tilde{5}_{\alpha}=[3+2 \alpha, 7-2 \alpha] ; \tilde{5}_{\alpha}^{-1}=\left[\frac{1}{7-2 \alpha}, \frac{1}{3+2 \alpha}\right] \ldots$.

$\tilde{7}_{\alpha}=[5+2 \alpha, 9-2 \alpha] ; \tilde{7}_{\alpha}^{-1}=\left[\frac{1}{9-2 \alpha}, \frac{1}{5+2 \alpha}\right]$

$\widetilde{9}_{\alpha}=[7+2 \alpha, 11-2 \alpha] ; \widetilde{9}_{\alpha}^{-1}=\left[\frac{1}{11-2 \alpha}, \frac{1}{7+2 \alpha}\right]$.

$\widetilde{\alpha_{1 j}^{\alpha}}=\omega \widetilde{\alpha_{1 j u}^{\alpha}}+(1-\omega) \widetilde{\alpha_{1 \jmath l}^{\alpha}} ; \vee \omega \epsilon[0,1] \ldots$

Perhitungan indeks konsistensi $(C I)$ dan rasio konsistensi $(C R)$ sesuai dengan persamaan 7 dan 8 (Saaty dan Vargas, 2012). Dimana, $\lambda_{\text {maks }}$ adalah nilai eigen maksimum, $n$ adalah banyaknya alternatif, dan $R I$ adalah random indeks.

$$
\begin{gathered}
C I=\frac{\left(\lambda_{\text {maks }}-n\right)}{n-1} \\
C R=\frac{C I}{R I} \quad \ldots \ldots \ldots . . .
\end{gathered}
$$

Tahap pengembangan terdiri dari penyesuaian dan evaluasi. Penyesuaian dilakukan terhadap bobot parameter yang akan dikonversi ke menjadi bobot ordinal, sedangkan evaluasi dilakukan terhadap perhitungan kinerja, biaya dan value pada setiap alternatif purwarupa. Bobot ordinal merupakan bobot yang diurutkan dari yang terendah hingga tertinggi dan sebaliknya (Marimin dan Maghfiroh, 2010). Hal itu dilakukan untuk dapat melakukan perhitungan kinerja purwarupa kemasan dengan metode perbandingan eksponensial (MPE). Adapun kelebihan metode MPE adalah nilai skor yang menggambarkan urutan prioritas menjadi lebih besar (lebih nyata) sehingga dapat mengurangi bias yang mungkin terjadi dalam analisa (Marimin dan Maghfiroh, 2010).

$$
\text { Total nilai }\left(T N_{i}\right)=\sum_{j=i}^{m}\left(R K_{i j}\right)^{T K K_{j}}
$$

Keterangan:

$$
\begin{aligned}
T N_{i} & =\text { total nilai ke-i; } R K_{i j} \\
R K_{i j} & =\begin{array}{l}
\text { derajat kepentingan relative kriteria } \\
\text { ke-j pada keputusan } \mathrm{i}
\end{array} \\
T K K_{j} & =\begin{array}{l}
\text { derajat kepentingan kriteria } \\
\text { keputusan ke-j }
\end{array} \\
m & =\text { jumlah kriteria keputusan }
\end{aligned}
$$

Purwarupa dibentuk dengan memberikan label yang berbahan stiker kromo pada 3 alternatif kemasan pouch. Label tersebut dicetak melalui mesin digital printing dengan area cetak $31 \mathrm{~cm} \mathrm{x} 47 \mathrm{~cm}$. Ukuran label sebelumnya $7 \mathrm{~cm} \times 10 \mathrm{~cm}$, tetapi untuk ukuran label alternatif dioptimalkan menjadi 7,5 cm x $10 \mathrm{~cm}$ karena biaya yang dikeluarkan masih sama. Penilaian dilakukan oleh konsumen umum terhadap kemasan kondisi awal dan 3 alternatif purwarupa kemasan dengan skala likert. Sementara itu, nilai yang diperhitungkan adalah modus dari penilaian konsumen.

Evaluasi alternatif yang dipilih adalah alternatif yang memiliki nilai (value) tertinggi. Nilai tertinggi merupakan desain kemasan yang memiliki daya tarik terbaik tetapi juga memiliki nilai yang 
ekonomis. Perhitungan nilai (value) menggunakan formula 9 dan 10 yang diadaptasi dari Cahyono dan Trisunarno (2012):

$$
V=\frac{P}{C}
$$

Keterangan:

$$
\begin{aligned}
P= & \text { nilai kinerja yang diperoleh dari hasil } \\
& \text { perkalian bobot dengan penilaian } \\
& \text { konsumen (modus) }
\end{aligned}
$$

Dalam perhitungan value $(V)$ dilakukan konversi dengan mengasumsikan value $(V)$ awal adalah 1. Nilai kinerja dikonversi menjadi kinerja dengan satuan rupiah. Pada tahap pengembangan dilakukan perbaikan terhadap desain kemasan terpilih. Tahap akhir berupa rekomendasi alternatif terbaik yang dilengkapi dengan filosofi dan informasi teknis produksinya

$$
C_{n}^{\prime}=\frac{P_{n} \cdot C_{0}}{P_{0}}
$$

Keterangan:

$$
\begin{aligned}
& P_{0}=\text { kinerja desain awal } \\
& P_{n}=\text { kinerja alternatif produk ke-n } \\
& C_{0}=\text { biaya desain awal } \\
& C_{n}^{\prime}=\text { kinerja alternatif dalam rupiah }
\end{aligned}
$$

Perhitungan biaya dilakukan dengan asumsi biaya 1 pouch dan 1 label. Konversi nilai kinerja dilakukan kedalam satuan rupiah agar satuan rupiah habis dibagi. Untuk memudahkan konversi, maka nilai awal diasumsikan 1. Hasil akhir dari tahap pengembangan berupa value yang merupakan nilai kinerja dibagi dengan biaya.

Terakhir, tahap rekomendasi merupakan tahap yang bersifat memberikan rekomendasi model desain kemasan yang paling tepat untuk pelaku usaha mikro kopi specialty berdasarkan penelitian.

\section{HASIL DAN PEMBAHASAN}

\section{Tahap Informasi}

Wahyudi dan Satriyono (2017) menyebutkan bahwa ada beberapa alasan re-desain kemasan: 1) untuk produk baru; 2) karena tekanan persaingan; 3) untuk reposisi produk; 4) untuk perluasan produk; 5) untuk promosi khusus. Reposisi produk menjadi alasan utama dalam re-desain ini mengingat perlunya up to date menghadapi persaingan yang semakin luas.
ARAKOPI menjual kopi arabika Gayo yang merupakan kopi yang sudah dikenal oleh pasar domestik maupun Internasional. Usaha ini selalu berupaya untuk memberikan kopi yang sehat dan bermanfaat yang tepat guna untuk lingkungan dan masyarakat setempat. Namun harus bisa juga mengkomunikasikan identitas produk kepada calon konsumen agar dapat bersaing dengan usaha pabrikasi yang besar.

Identifikasi keinginan dan harapan pelaku usaha ARAKOPI dituangkan kedalam ringkasan desain. Ringkasan desain merupakan gambaran awal suatu proyek desain, dalam hal ini desain kemasan untuk produk ARAKOPI. Tujuannya agar mampu memberikan informasi, arahan, dan sasaran secara global dengan tepat. Ringkasan desain dapat dilihat pada Tabel 1 .

Bagian terpenting dari ringkasan desain adalah tone and manner yang digunakan dalam penelitian ini sebagai dasar visualisasi pada tahap kreatif untuk memperoleh kemasan yang berkarakter dengan memperhatikan segmen pasar atau target konsumen. Penetapan jenis pouch didasarkan pada trend kemasan kopi yang digunakan oleh kompetitor. Penggunaan kemasan jenis pouch yang ditempel label bertujuan agar mudah dalam memperoleh kemasan dalam jumlah yang sesuai dengan kebutuhan atau kemampuan pelaku usaha.

Konten pada label terdiri dari identitas produk kopi, nama perusahaan, cara penyajian, cara penyimpanan, fisik produk, dan berat isi. Copywriting required diperoleh dari hasil diskusi dengan pelaku usaha. Tabel 2 menunjukkan informasi danInformasi dan copywriting required. Jenis karakteristik citarasa dituliskan dituliskan dalam bahasa Inggris karena memang sudah populer di kalangan pecinta kopi.Informasi ini sangat penting karena konsumen bersedia membayar lebih untuk produk terkemuka jika mereka mendapat informasi yang dibutuhkan(Corso dan Benassi, 2015).

Merujuk pada Zulkarnain et al. (2018) bahwa konsumen cenderung memilih kemasan yang memiliki fitur zipper. Namun, fitur zipper hanya ada pada pouch tipe stand up pouch dan flat bottom pouch. Oleh karenanya, dalam penelitian ini tipe side gusset pouch tidak digunakan sebagai alternatif. Warna dasar kemasan yang digunakan adalah hitam. Hal ini sesuai dengan penelitian hasil Harith et al. (2014) yang menyebutkan bahwa kemasan kopi umumnya berwarna gelap. Dimensi stand up pouch lebih besar dibanding flat bottom pouch walaupun memiliki volume yang sama, yaitu $100 \mathrm{~g}$. Alternatif 1 dan 2 menggunakan tipe pouch yang sama dengan kondisi kemasan saat ini untuk menghindarkan peningkatan biaya. Spesifikasi alternatif struktur kemasan dapat dilihat pada Tabel 3.

Tabel 1. Ringkasan desain kemasan untuk produk ARAKOPI

Brand/Project ARAKOPI




\begin{tabular}{ll}
\hline Project Name & Re-Desain Kemasan ARAKOPI \\
\hline $\begin{array}{l}\text { Project } \\
\text { Background }\end{array}$ & $\begin{array}{l}\text { Meningkatnya minat konsumen terhadap kopi berkualitas membuat setiap kopi specialty } \\
\text { membutuhkan kemasan yang memiliki daya tarik lebih untuk menunjukkan kualitas } \\
\text { produknya, sehingga dapat menambah konsumen baru dan meningkatkan penjualannya. }\end{array}$ \\
\hline $\begin{array}{l}\text { Product } \\
\text { Knowledge }\end{array}$ & $\begin{array}{l}\text { ARAKOPI merupakan 100\% Kopi Arabika Gayo (Aceh) yang terkenal di berbagai } \\
\text { belahan dunia. Kopi ini memiliki penilaian aroma dan rasa yang istimewa, diatas kopi } \\
\text { rata-rata pada umumnya dengan kualitas specialty (terbaik). Memiliki karakter yang } \\
\text { membuatnya unik dan menarik .Hadir dalam bentuk ground maupun whole bean. Harga } \\
\text { jual ARAKOPI yang specialty sebesar Rp 75.000 per 250 gr dengan segmen pasar } \\
\text { Indonesia. Tersedia juga ukuran 100 gr (Rp 30.000) dan 500 gr (RP 165.000). }\end{array}$ \\
\hline $\begin{array}{l}\text { Competitors } \\
\text { Information }\end{array}$ & $\begin{array}{l}\text { Semua produk kopi specialtysingle origin dalam kemasan seperti Carve, Northider, } \\
\text { Saturdays Coffee, Mr.O Coffee, JPW Coffee, Seven Bika Coffee, Fry Roast, Marones } \\
\text { Coffee, Kebon Kopi, Noah's Barn, Malabar Mountain Coffee, Tobi's, dan lain-lain. }\end{array}$ \\
\hline Objectives & $\begin{array}{l}\text { Merancang ulang (re-desain ARAKOPI) label kemasan yang mampu diterima pasar } \\
\text { dengan biaya rendah, tetapi mudah dalam perolehan label dan kemasannya. }\end{array}$ \\
\hline Target Audience & $\begin{array}{l}\text { Pria dan wanita, usia 20-55 tahun (remaja - orang tua) dengan kelas sosial menengah ke } \\
\text { atas }\end{array}$ \\
\hline Key Message & Keaslian cita rasa dan aroma khaskopi Gayo \\
\hline $\begin{array}{l}\text { Mandotary } \\
\text { Element }\end{array}$ & Buat logo baru \\
\hline $\begin{array}{l}\text { Design Tone and } \\
\text { Manner }\end{array}$ & Akrab (friendly); premium; simpel; spesial \\
\hline $\begin{array}{l}\text { Media Details/ } \\
\text { Design Items }\end{array}$ & $\begin{array}{l}\text { Kemasan dengan jenis pouch; Bagian dalamnya (inner) berbahan aluminium foil; } \\
\text { Menggunakan zipper dan valve; Ukuran kemasan pouch 100 g; Desain grafis kemasan } \\
\text { diaplikasikan pada label. }\end{array}$ \\
\hline
\end{tabular}

Tabel 2. Informasi dan copywriting required

\begin{tabular}{ll}
\hline Informasi & Copywriting required \\
\hline Identitas produk kopi & Lokasi perkebunan: Takengon Indonesia \\
& Informasi geografis: Gayo \\
& Ketinggian tanam: $1500 \mathrm{~m}-1600 \mathrm{~m}$ \\
& Karakteristik citarasa $($ note): medium acidity, medium body, rich aroma and \\
& flavor \\
& Nama merek: Arakopi \\
& Nama produk: Kopi Arabika Gayo \\
& Tanggal roasting: 17 April 2019 \\
\hline Nama perusahaan & Diproduksi oleh: Arakopi \\
\hline Cara penyajian & Saran penyajian/ saran teknik seduh: French press atau diseduh langsung \\
\hline Cara penyimpanan & Setelah kemasan dibuka, segera tutup kembali \\
\hline Fisik produk & Bubuk / biji \\
\hline Berat isi & Berat Bersih: $100 \mathrm{~g}$ \\
\hline
\end{tabular}

Tabel 3. Spesifikasi alternatif struktur kemasan

\begin{tabular}{lcccc}
\hline Struktur Kemasan & Jenis Pouch (100 g) & Zipper & $\begin{array}{c}\text { Warna } \\
\text { Dasar }\end{array}$ & Dimensi (cm) \\
\hline Kondisi saat ini & Stand Up Pouch & Standard zipper & Putih & $12 \times 20 \times 8$ \\
Alternatif I & Stand Up Pouch & Standard zipper & Hitam & $12 \times 20 \times 8$ \\
Alternatif II & Stand Up Pouch & Standard zipper & Hitam & $12 \times 20 \times 8$ \\
Alternatif III & Flat Bottom Pouch & Pocket zipper & Hitam & $9,5 \times 18,5 \times 6$ \\
\hline
\end{tabular}

\section{Tahap Kreatif}

Tahap ini terdiri darimoodboard, sketsa, digitalisasi desain, hingga purwarupa. Berdasarkan pada ringkasan desain (design brief) dan moodboard yang telah disusun, tiga sketsa dan hasil digitalisasi desain label yang dirancang secara berbeda dapat dilihat pada Gambar 3. Label tersebut digunakan sebagai sarana untuk menguatkan branding produk kopi karena biasanya calon konsumen melihat dan membaca label kemasan sebelum memutuskan untuk membeli. Label yang ditempel pada kemasan sangat tepat untuk usaha mikro karena memungkinkan untuk diperoleh dalam jumlah yang sedikit sehingga biaya investasi untuk kemasan pun tidak terlalu tinggi. Apalagi kemasan dengan label yang menarik sampai saat ini masih banyak diminati. 
Kemasan dituntut untuk menarik secara visual karena berperan kemasan sebagai media komunikasi yang berhadapan langsung dengan konsumen. Biasanya konsumen mengenal pola-pola visual, maka diperlukan rancangan yang mudah dikenal dan diingat kembali. Untuk itu perlu ditangani secara sungguh-sungguh dalam setiap prosesnya. Apalagi proses afektif dan kognitif memiliki peran penting dalam preferensi estetika (Chind dan Sahachaisaeree, 2012). Dalam membuat pola-pola visual baik warna, tipografi, citra, maupun tata letaknya mengacu pada tone and manner.

Tone and manner yang digambarkan pada setiap alternatif desain ini adalah akrab (friendly), premium, simpel, dan spesial. Akrab (friendly) digambarkan dengan ornamen gayo sebagai simbol kearifan lokal yang akrab dikenal oleh masyarakat Indonesia dan maupun dunia. Premium digambarkan dengan warna-warna keemasan mengindikasikan tingkat kemahalan (premium) produk di dalam kemasan. Simpel digambarkan dengan penggunaan ilustrasi yang tidak rumit, warna yang tidak banyak, font yang didominasi oleh sans serif. Terakhir, spesial digambarkan dengan gerakan asap yang keluar dari cangkir menyebarkan aroma yang spesial dan biji-biji kopi yang menunjukkan kekhasan cita rasa kopi yang spesial.

Ornamen Gayo pada alternatif desain kemasan I mempertegas kearifan lokal yang akrab dikenal dunia. Kemudian memadukan warna cokelat muda dan cokelat tua sebagai gambaran biji matang sempurna (roasted). Warna putih dan hitam yang simpel menunjukkan kemurnian kopi single origin. Sebaran biji-biji kopi yang kelap-kelip dengan latar belakang (background) hitam mempertegas kesan produk yang premium.

Tumpukan bata pada alternatif desain kemasan II menunjukkan eksistensi produk ini terus tumbuh dan menguat. Perpaduan warna hitam dan oranye memberikan suasana yang akrab sekaligus premium di mata yang melihatnya. Ornamen gayo di bagian kiri dan kanan sebagai menanda bahwa produk ini dihadirkan secara spesial dari Gayo. Semua elemen dipadu secara simpel. Sementara itu alternatif desain kemasan III menceritakan secangkir kopi yang berwarna emas menyebarkan aroma kopi lewat gerakan asap dan sebaran biji-biji kopi. Hal ini mempertegas sebagai sesuatu yang akrab, premium, simpel, sekaligus spesial. Dominasi warna hitam sebagai penguat sisi premium produk. Ornamen Gayo menunjukkan identitas asal produk kopi.
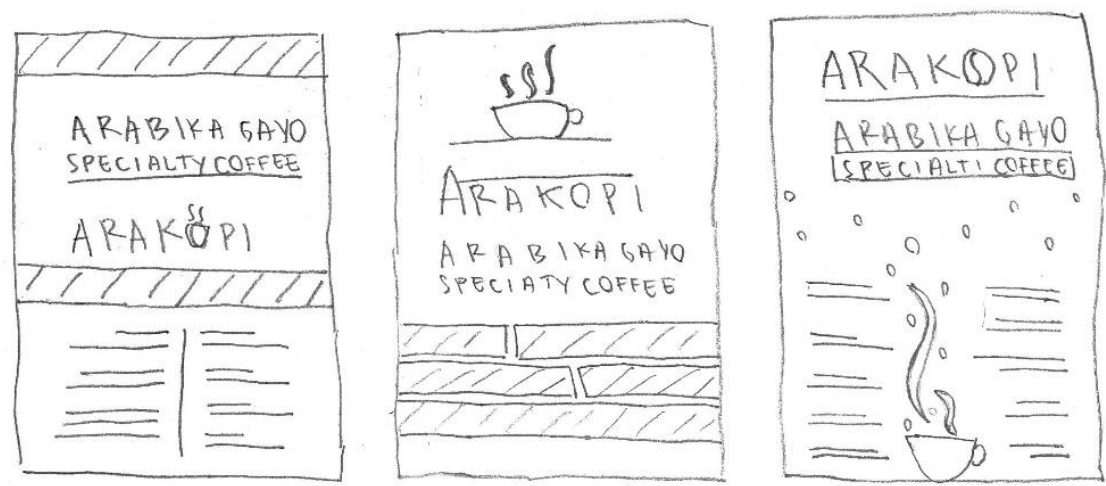

(a)

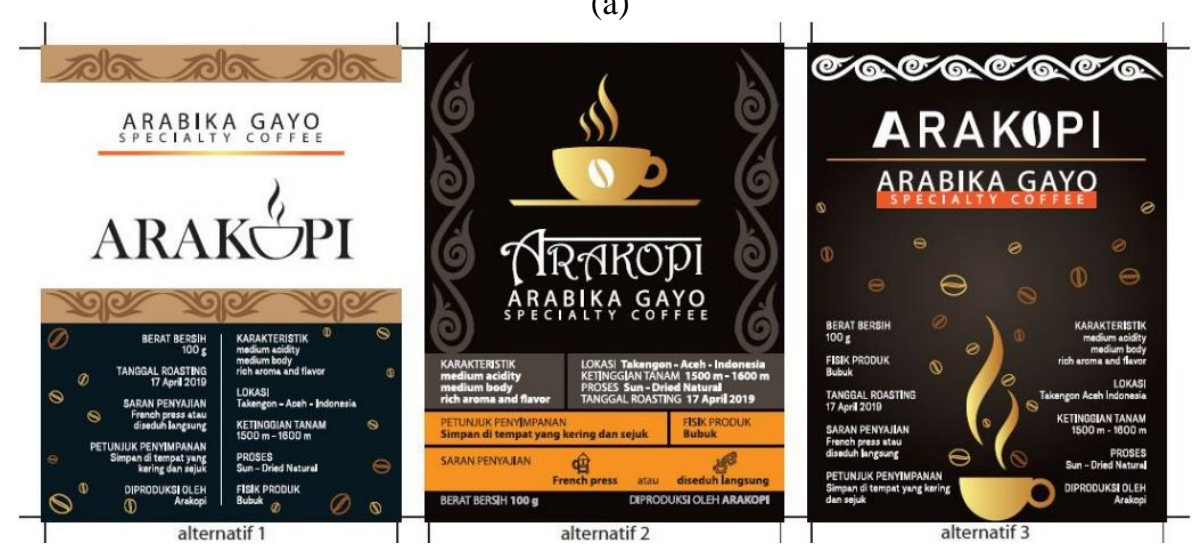

(b)

Gambar 3. Sketsa (a) dan digitalisasi (b) desain label kemasan 


\section{Tahap Analisis}

Menurut (Rusko et al., 2011), kemasan harus mencapai tujuan yang lebih konkret terkait kemasan sebagai elemen komunikasi yang digambarkan dalam bentuk hirarki pada Gambar 4. Hierarki tersebut digunakan sebagai parameterparameter untuk memperoleh pembobotan matriks pengukuran kinerja kemasan. Tiga level dalam hierarki ini, yaitu komunikasi kemasan, elemen desain kemasan, dan parameter kinerja.

Level komunikasi (message) kemasan terdiri dari tiga dimensi: informasi fakta, aspek fungsional, konten emosional. Informasi fakta merupakan media petunjuk bagi para konsumen. Aspek fungsional yang dimaksud adalah kemasan sesuai dengan tujuan dan produknya, sedangkan yang dimaksud konten emosional yaitu kemasan harus mampu memberikan dorongan hati tanpa disadari (respons positif) konsumen.

Semua komunikasi kemasan bermuara ke elemen desain kemasan yang terdiri dari elemen struktur dan elemen grafis (Rusko et al., 2011). Hal ini didukung oleh Chind dan Sahachaisaeree (2012) yang menyatakan bahwa elemen desain kemasan mempengaruhi persepsi konsumen dalam menyampaikan nilai produk yang mengarah kepada keputusan pembelian.

Elemen struktur dalam penelitian ini terdiri dari bentuk, ukuran, dan bahan. Bentuk yang dimaksud adalah bentuk pouch, ukuran yang dimaksud merupakan ukuran dimensi pouch, dan bahan yang dimaksud merupakan bahan permukaan pouch, sedangkan elemen grafis dalam penelitian ini terdiri dari warna, tipografi, dan citra. Warna yang dimaksud merupakan warna label yang dilihat secara keseluruhan dan kesatuan dengan warna dasar pouch, tipografi yang dimaksud merupakan jenis huruf, ukuran huruf, tata letak teks, keterbacaan yang dilihat secara keseluruhan dan kesatuan. Lalu yang dimaksud dengan citra merupakan gambar/ilustrasi, simbol, ikon, dan ornamen yang dilihat secara keseluruhan dan kesatuan juga.

Para pakar memberikan penilaian dengan skala $\tilde{1}$ (sama penting), $\tilde{3}$ (sedikit lebih penting), $\tilde{5}$ (lebih penting), $\tilde{7}$ (sangat lebih penting), dan $\tilde{9}$ (mutlak lebih penting). Data rekapitulasi diolah dengan metode fuzzy AHP. Berdasarkan perhitungan metode fuzzy AHP diperoleh bahwa semua nilai rasio konsistensi menunjukkan angka dibawah 0,1 yang berarti bahwa pakar cukup konsisten dalam memberikan penilaian. Hasil perhitungan pada level elemen desain kemasan menunjukkan bahwa bobot elemen grafis lebih besar dibanding elemen struktur. Hal ini mengindikasikan bahwa kecenderungan fungsi grafis lebih besar daripada fungsi praktis dalam mempengaruhi konsumen. Senada dengan penelitian Elham dan Ehsan (2015) dan Steenis et al. (2017) yang menyatakan bahwa penilaian konsumen sangat dipengaruhi oleh elemen grafis yang menimbulkan kesan produk sehingga memiliki efek pada penjualan dan pemasaran.

\section{Tahap Pengembangan}

Bobot parameter kinerja terbesar pada elemen struktur secara berturut-turut adalah ukuran, bahan, dan bentuk. Sementara bobot parameter kinerja terbesar pada elemen grafis secara berturutturut adalah warna, tipografi, dan citra. Ukuran memperoleh bobot tertinggi diantara jenis elemen struktur karena konsumen lebih mengutamakan ukuran sebagai pertimbangan konsumsi dan kemudahan dibawa, sedangkan, warna memperoleh bobot tertinggi diantara jenis elemen grafis karena warna lebih mudah direspon oleh penglihatan. Bobotbobot parameter (b) yang telah diperoleh dikonversi menjadi bobot ordinal. Proses konversi bobot dapat dilihat pada Tabel 4 sedangkan kinerja purwarupa dilihat pada Tabel 5 .

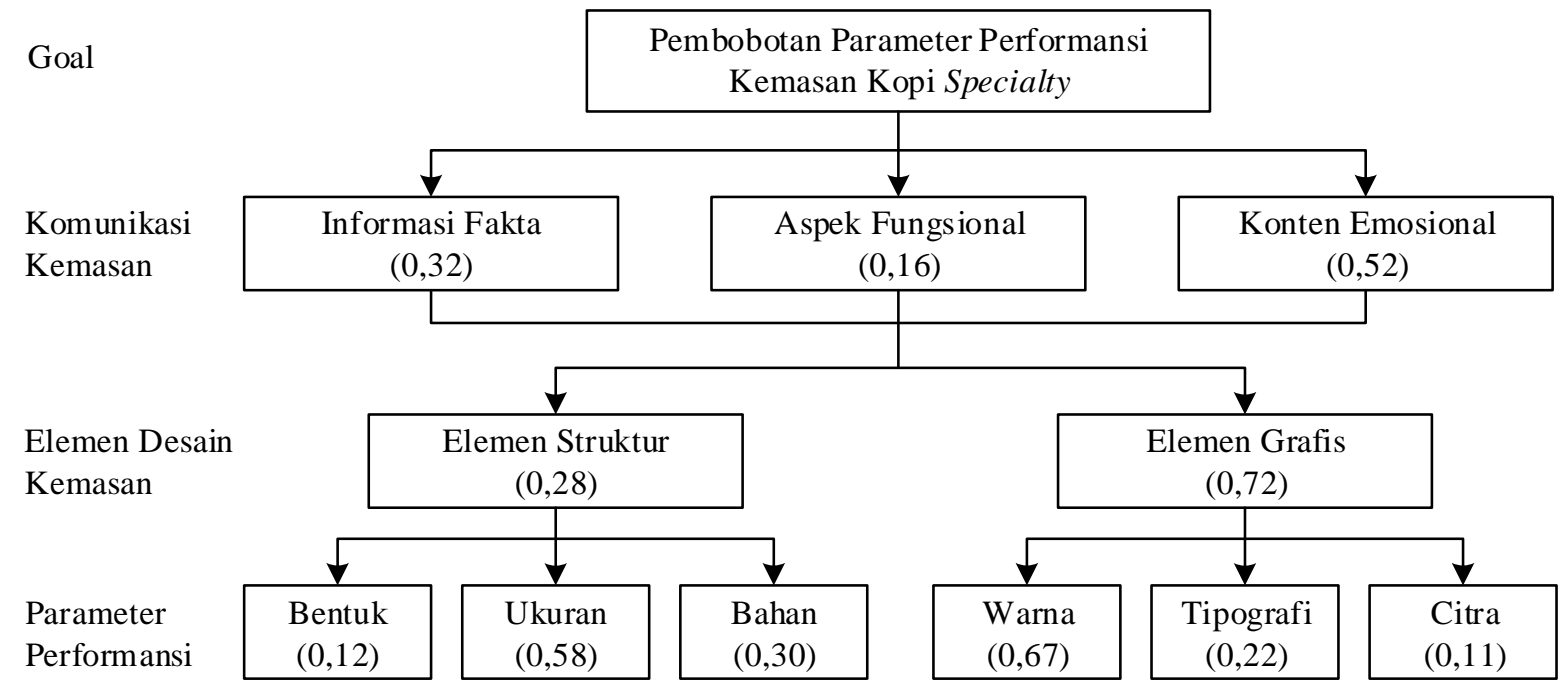

Gambar 4. Hirarki pembobotan parameter kinerja kemasan 
Tabel 4. Konversi bobot

\begin{tabular}{llccc}
\hline Elemen (a) & Parameter(b) & $\begin{array}{c}\text { Bobot Rasio } \\
(\mathbf{a ~ x ~ b )}\end{array}$ & Rangking & $\begin{array}{c}\text { Bobot } \\
\text { Ordinal }\end{array}$ \\
\hline \multirow{3}{*}{ Struktur $(0,28)$} & Bentuk $(0,12)$ & 0,03 & 5 & 1 \\
& Ukuran $(0,58)$ & 0,16 & 2 & 4 \\
& Bahan $(0,30)$ & 0,08 & 4 & 2 \\
Grafis $(0,72)$ & Warna $(0,67)$ & 0,48 & 1 & 5 \\
& Tipografi $(0,22)$ & 0,15 & 3 & 3 \\
& Citra $(0,11)$ & 0,08 & 4 & 2 \\
\hline
\end{tabular}

Tabel 5. Kinerja purwarupa kemasan

\begin{tabular}{lccccc}
\hline \multirow{2}{*}{ Parameter } & \multirow{2}{*}{$\begin{array}{c}\text { Bobot } \\
\text { Ordinal }\end{array}$} & Kondisi saat ini & \multicolumn{3}{c}{ Penilaian } \\
\cline { 3 - 6 } & & & I & II & III \\
\hline Bentuk & 1 & 5 & 7 & 7 & 7 \\
Ukuran & 4 & 7 & 5 & 5 & 7 \\
Bahan & 2 & 5 & 7 & 7 & 7 \\
Warna & 5 & 5 & 7 & 7 & 7 \\
Tipografi & 3 & 5 & 7 & 7 & 7 \\
Citra & 2 & 3.956 & 17.880 & 17.880 & 19.656 \\
\hline
\end{tabular}

Keterangan penilaian: 1 = tidak bagus; $3=$ kurang bagus; 5 = biasa; 7 = bagus; $9=$ sangat bagus; Nilai $2,4,6$, dan 8 merupakan nilai-nilai diantara dua nilai pertimbangan yang berdekatan.

Responden (konsumen umum) yang memberikan penilaian purwarupa kemasan berasal dari berbagai provinsi, seperti Aceh, Sumatra Utara, Riau, Sumatra Barat, Lampung, Banten, Jakarta, Jawa Barat, Jawa Tengah, dan Jawa Timur. Responden memiliki kebebasan dalam memilih produk meskipun yang terlihat hanya kemasannya saja karena produknya di dalam kemasan. Penilaian kinerja desain kemasan dilakukan oleh konsumen berdasarkan bentuk, ukuran, bahan, warna, tipografi, dan citra. Tujuan evaluasi ini adalah untuk memahami model kemasan yang mampu mendorong konsumen untuk melakukan keputusan pembelian. Purwarupa kemasan dapat dilihat pada Gambar 5.

Berdasarkan perhitungan kinerja alternatif purwarupa kemasan pada Tabel 5 diperoleh kinerja tertinggi adalah desain kemasan alternatif III, kemudian pada alternatif I dan II memiliki kinerja yang sama. Alternatif III memperoleh kinerja tertinggi diantara alternatif yang lainnya karena memiliki ukuran dimensi yang agak padat (compact) sehingga menimbulkan daya tarik konsumen dalam hal kemudahan dipegang, dibawa, dipajang, dan disimpan. Sementara itu, desain kemasan yang kondisi awal memperoleh kinerja terkecil. Hal ini menunjukkan bahwa re-desain kemasan telah berhasil meningkatkan kinerja kemasan pada setiap alternatifalternatif desain kemasan sehingga dapat diharapkan menambah daya tarik bagi konsumen untuk keputusan pembelian.

Biaya yang digunakan adalah biaya per satuan label. Untuk biaya label diasumsikan minimum dalam sekali cetak 100 lembar yang setiap lembarnya Rp 6.000. Dalam 1 lembar dapat memuat 18 bagian label. Hal ini berarti 1 bagian label memiliki biaya Rp 334. Biaya satuan struktur stand up pouch sebesar Rp 5.632, sedangkan biaya satuan struktur flat bottom pouch sebesar Rp 6.666. Jadi biaya (C) pada kondisi awal, alternatif I, dan II masing-masing adalah Rp $334+\operatorname{Rp} 5.632=\operatorname{Rp} 5.966$, sedangkan biaya (C) pada alternatif III adalah Rp 334 $+\mathrm{Rp} 6.666=\mathrm{Rp} 7.000$.

Berdasarkan hasil perhitungan, diperoleh urutan value dari yang tertinggi adalah alternatif I dan II, kemudian III. Value pada alternatif III berada pada posisi kedua karena dipengaruhi oleh faktor biaya (C) yang lebih besar dari alternatif lainnya, sedangkan kemasan kondisi awal memperoleh value terkecil karena kinerjanya yang juga paling kecil. Meskipun alternatif III memiliki kinerja (P) terbesar, namun memiliki value lebih kecil diantara alternatif lainnya, karena dipengaruhi oleh faktor biaya yang lebih besar dibanding alternatif lainnya.Namun yang tetap menjadi perhatian penting adalah alternatif IIImemiliki kinerja (P) terbesar. Value setiap alternatif ditunjukkan pada Tabel 6.

\section{Tahap Rekomendasi}

Kemasan yang tepat bagi industri mikro adalah kemasan yang desain permukaannya terdapat pada label. Hal ini karena label dapat dipesan/dicetak tanpa jumlah minimum (on demand) pada printing services sehingga tidak terlalu membebanikemampuan modal industri mikro. Struktur kemasan jenis pouch sangat tepat digunakan untuk produk kopi. Hal ini karena jenis pouch dapat disematkan fitur valve dan zipper yang dibutuhkan oleh produk kopi. Selain itu kemasan jenis pouch merupakan kemasan yang dapat dipesan/dibeli dengan jumlah minimal yang relatif sedikit (on demand) pada pemasok kemasan. Jika bentuk dan bahan kemasan telah standard, maka elemen grafis pada kemasan merupakan faktor penentu menarik atau tidaknya sebuah kemasan (Natadjaja, 2007). 


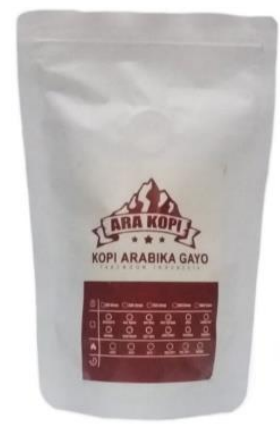

kondisi awal

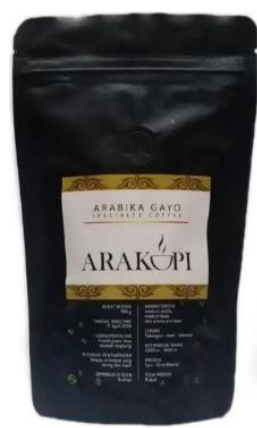

Alternatif I

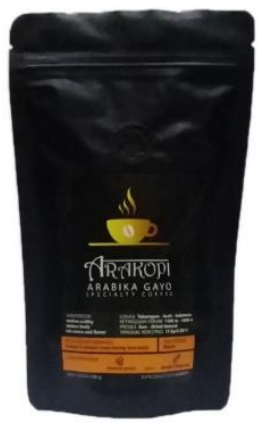

Alternatif II

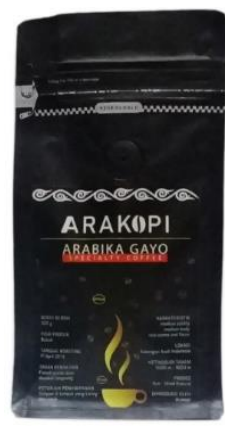

Alternatif III

Gambar 5. Kemasan kondisi awal dan tiga alternatif purwarupa

Tabel 6. Value setiap alternatif

\begin{tabular}{llcccc}
\hline No. & Alternatif & Kinerja $(\boldsymbol{P})$ & Biaya $(\boldsymbol{C})$ & $\begin{array}{c}\text { Konversi kinerja ke } \\
\text { dalam rupiah }(\boldsymbol{P})\end{array}$ & Value \\
\hline 1 & Kondisi saat ini & 3.956 & $\mathrm{Rp} \mathrm{5.966}$ & $\mathrm{Rp} \mathrm{5.966,0}$ & 1,0 \\
2 & I & 17.880 & $\mathrm{Rp} \mathrm{5.966}$ & $\mathrm{Rp} \mathrm{26.964,6}$ & 4,5 \\
3 & II & 17.880 & $\mathrm{Rp} \mathrm{5.966}$ & $\mathrm{Rp} \mathrm{26.964,6}$ & 4,5 \\
4 & III & 19.656 & $\mathrm{Rp} \mathrm{7.000}$ & $\mathrm{Rp} \mathrm{29.643,0}$ & 4,2 \\
\hline
\end{tabular}

Struktur kemasan yang on demand dan desain permukaan pada label dapat menjadi strategi yang tepat bagi industri mikro. Kemasan yang tepat dan menarik tidak harus dengan biaya yang tinggi. Kemasan yang ditempel dengan label, jika dirancang dengan baik akan menjadi kemasan yang memiliki daya jual yang tinggi.

Purwarupa yang dirancang memiliki bentuk, ukuran, dan bahan sama dengan kemasan yang sebenarnya tetapi tidak produksi massal karena purwarupa ini ditujukan untuk evaluasi kesukaan konsumen. Spesifikasi teknis purwarupa dapat dilihat pada Tabel 7. Berdasarkan struktur isi, jenis purwarupa kemasan yang dirancang merupakan kemasan primer karena langsung mewadahi produk kopi, sedangkan jika berdasarkan frekuensi pemakaiannya termasuk jenis kemasan yang tidak dibuang (semi disposable) karena kemasan ini bisa digunakan untuk kepentingan lain setelah dipakai. Namun berdasarkan tingkat kesiapan pakai, kemasan ini termasuk jenis kemasan siap pakai karena secara struktur sudah sempurna sehingga hanya membutuhkan dekorasi agar lebih menarik.

Berdasarkan hasil penelitian, elemen grafis memiliki bobot yang lebih besar daripada elemen struktur untuk evaluasi purwarupa. Artinya, pelaku usaha harus memberi perhatian elemen grafis yang lebih besar daripada elemen struktur karena struktur kemasan kopi specialty umumnya menggunakan jenis yang sama (pouch). Jadi, elemen grafis harus lebih berperan agar produk dapat tampil lebih menarik dan lebih berdaya saing.

Desain alternatif label I, II, dan III dapat menjadi pilihan karena memiliki kinerja yang sama tinggi pada parameter elemen grafis. Namun, model yang paling tepat sebagai representasi kemasan untuk pelaku usaha kopi specialty untuk skala industri mikro adalah kemasan tipe flat bottom pouch yang terdapat pada alternatif III. Flat bottom pouch menjadi rekomendasi karena memiliki kinerja yang paling tinggi sehinggga dapat berdampak pada daya jual yang tinggi juga. Agar hasil cetak label lebih kuat dan tahan gesekan sebaiknya setelah dicetak label tersebut dapat dilaminasi.

Tabel 7. Spesifikasi teknis purwarupa kemasan kopi

\begin{tabular}{lll}
\hline \multicolumn{2}{l}{ Struktur } & Spesifikasi \\
\hline 1 & Jenis pouch & Stand up pouch \\
2 & Warna & Hitam \\
3 & Dimensi & $12 \mathrm{~cm}$ x $20 \mathrm{~cm}$ x $8 \mathrm{~cm}$ \\
4 & Kapasitas & $100 \mathrm{~g}$ \\
5 & Zipper & Standard zipper \\
6 & Valve & Ada \\
\hline Label & Spesifikasi \\
\hline 1 & Ukuran label & $7.5 \mathrm{~cm}$ x $10 \mathrm{~cm}$ \\
2 & Bahan cetak & Stiker kromo \\
3 & Teknik cetak & Digital printing \\
4 & Tinta & Warna \\
\hline
\end{tabular}

\section{Implikasi Manajerial}

Berdasarkan hasil penelitian model purwarupa kemasan, diharapkan dapat membantu usaha mikro kopi specialty dalam menghadapi hal teknis perancangan kemasan. Hal teknis tersebut seperti ringkasan desain (design brief), copywriting, spesifikasi struktur kemasan, label kemasan, asumsi biaya, visualisasi kemasan, dan lainnya. Pelaku usaha hendaknya memperhatikan hal teknis tersebut agar pengembangan desain kemasan menjadi lebih baik dan profesional. Pengembangan desain kemasan bukanlah hal sederhana, namun dapat dilakukan dengan mengikuti tahapan-tahapan dalam penelitian ini untuk memperoleh hasil optimal. Desain kemasan 
yang memiliki nilai estetis dan informasi yang baik dapat menjadi representasi produk yang ditawarkan sehingga dapat memberikan dampak emosional bagi konsumen.

\section{KESIMPULAN DAN SARAN}

\section{Kesimpulan}

Aktor Bobot parameter terbesar pada kinerja kemasan adalah warna, sehingga parameter tersebut harus lebih diperhatikan dalam merancang kemasan kopi specialty tanpa melupakan parameter lainnya. Kinerja model purwarupa tertinggi adalah alternatif III, kemudian pada alternatif I dan II memiliki kinerja yang sama, sedangkan urutan value dari yang tertinggi adalah alternatif I dan II, kemudian III. Desain alternatif label I, II, dan III dapat menjadi pilihan karena memiliki kinerja yang sama tinggi pada parameter elemen grafis. Namun, model yang paling tepat sebagai representasi kemasan untuk pelaku usaha kopi specialty untuk skala industri mikro adalah kemasan tipe flat bottom pouch yang terdapat pada alternatif III.

\section{Saran}

Penelitian ini telah mengintegrasikan proses engineering design dengan proses graphic design. Penelitian lebih lanjut dapat mengkaji dengan menggunakan alternatif-alternatif desain yang lebih bervariasidalam sebuah proses desain kemasan.

\section{UCAPAN TERIMA KASIH}

Terima kasih kepada Kementerian Ristekdikti melalui Direktorat Jenderal Pendidikan Tinggi sebagai pemberi Beasiswa Pendidikan Pascasarjana Dalam Negeri (BPPDN) program Doktor pada Program Studi Teknologi Industri Pertanian di Institut Pertanian Bogor (IPB) yang telah menunjang penelitian ini.

\section{DAFTAR PUSTAKA}

Auttarapong D. 2012. Package design expert system based on relation between packaging and perception of customer. Procedia Engineering. 32: 307 - 314.

Cahyono MJN dan Trisunarno L. 2012. Penerapan metode value engineering pada pengembangan desain jamban sehat dan ekonomis (Studi Kasus: Pengusaha Sanitasi Jawa Timur). Jurnal Teknik ITS. 1: 506-509.

Cerqueiro J, López L, dan Pose J. 2011. A proposal to incorporate the Value Analysis/Value Engineering techniques into a PLM system. Proceedings of the IMProVe 2011. June 15th -17 th, Venice, Italy: 140-149.

Chind K dan Sahachaisaeree N. 2012. Purchasers' Perception on packaging formal design: a comparative case study on luxury goods merchandizing. Procedia-Social and Behavioral Sciences. 42:436-442.

Corso MP dan Benassi MT. 2015. Packaging attributes of antioxidant-rich instant coffee and their influence on the purchase intent. Beverages. 1: 273-291. doi:10.3390/ beverages 1040273 .

[DJIKM] Direktorat Jenderal Industri Kecil Menengah. 2007. Pelatihan Kemasan [Modul]. Jakarta (ID): Departemen Perindustrian.

Elham S dan Ehsan V. 2015. Creative package, elevation in choices: the influence of packaging design on marketing and sales. Research Journal Recent Sciences. 4(4): 1519.

Hadiprawiro Y. 2018. Desain logo dan maskot "difabel klaten" sebagai brand awareness kampanye sosial peduli masyarakat disabilitas di Klaten, Jawa Tengah. Jurnal Desain. 5(2): 135-144.

Halder S, Ganguly D, dan Singh VP. 2016. Design process and its application on the improvement (re-design) of the coke bottle. International Journal Advanced Packaging Technology. 4(1): 185-199. https://doi.org/ 10.23953/ cloud.ijapt.23.

Hariono RF dan Zaini. 2017. Pengembangan desain kemasan sekunder parfum merk griya parfumes sidoarjo. Jurnal Pendidikan Seni Rupa. 5(1): 128-135.

Harith ZT, Ting CH, dan Zakaria NNA. 2014. Coffee packaging: Consumer perception on appearance, branding and pricing. International Food Research Journal, 21(3): 849-853.

Hidayat MJ, Faruk HT, Lastoro L, Amir Y. 2014. Ekspresi budaya visual UKM melalui desain kemasan. Jurnal IPTEK. 18(2):145-153.

Hess JS, Singh J, Metcalf LE, Danes J. 2014. The impact of consumer product package qualityon consumption satisfaction, brand perceptions, consumer investment and behavior. Journal Applied Packaging Research. 6(1): 23-39.DOI: 10.14448/ japr.01.0003.

Jadhav P dan Teli SN. 2015. Weight reduction of flywheel applying value engineering: a case study. International Journal Engineering Sciences \& Management Research. 2(10): 28-44.

Kun $\mathrm{G}$ dan Xi W. 2017. Design and analysis of cushioning packaging for home appliances. Procedia Engineering. 174: 904 - 909.

Kuvykaite R, Dovaliene A, dan Navickiene L. 2009. Impact of packaging elements on consumer's purchase decision. Economics\& Management. 14:441-447.

Marimin, Djatna T, Suharjito, Hidayat S, Utama DN, Astuti R, Martini S. 2013. Teknik dan 
Analisis Pengambilan Keputusan Fuzzy dalam Manajemen Rantai Pasok. Bogor (ID) : IPB Press.

Marimin dan Maghfiroh N. 2010. Aplikasi Teknik Pengambilan Keputusan dalam Manajemen Rantai Pasok. Bogor (ID) : IPB Press.

Murniyati. 2009. Penggunaan retort pouch untuk produk pangan siap saji. Squalen. 4(2): 5560.

Nadal M, Munar E, dan Capó MÀ. 2008. Towards a framework for the study of the neural correlates. Spatial Vision. 21(3): 379-396.

Natadjaja L. 2007. Analisa elemen grafis desain kemasan indomie goreng pasar lokal dan ekspor. Nirmana. 9(1):20-30.

Parada LR, Mayuet PF, dan Gámez. 2019. Custom design of packaging through advanced technologies: A case study applied to apples. Materials. 12(467): 1-19.

[PEGR] Philippine-Australia Partnership for Economic Governance Reforms. 2009. Value Analysis Handbook. Australia: National Economic and Development Authority of Australian Government.

Rundh B. 2016. The role of packaging within marketing and value creation. British Food Journal.118(10): 2491-2511. https://doi.org/10.1108/BFJ-10-2015-0390.
Rusko E, Heinio S, Korhonen V, Heilmann J, Karjalainen TM, Lahtinen P, Pitkanen M. 2011. Messenger package - integrating technology, design and marketing for future package communication [Final Report]. VTT Tiedotteita - Research Notes 2586. 90 p.

Saaty TL dan Vargas LG. 2012. Models, Methods, Concepts \& Applications of the Analytic Hierachy Process, 2nd ed. New York, US: Springer.

Steenis ND, Herpen EV, Lans IAVD, Ligthart TN, Trijp HCMV. 2017. Consumer response to packaging design: The role of packaging materials and graphics in sustainability perceptions and product evaluations. Journal Cleaner Production, 162: 286-298. http://dx.doi.org/10.1016/j.jclepro.2017.06. 036.

Younker DL. 2003. Value Engineering: Analysis and Methodology. New York: Marcel Dekker.

Wahyudi N dan Satriyono. 2017. Mantra Kemasan Juara. Jakarta: PT Elex Media Komputindo.

Zulkarnain, Machfud, Marimin, Darmawati E, Sugiarto. 2018. Model design of specialty coffee packaging structures. International Journal Advanced Research. 6(5): 494-505. 